\title{
Measuring Labor Market Dynamics: Gross Flows of Workers and Jobs
}

$G$ truction of specific jobs or the movement of workers into and out of employment-are the immediate outcomes of labor market processes. When a firm closes a plant, it destroys jobs. When it opens a plant, it creates jobs. When an adult leaves a job to return to school full time or take care of a child, there is a flow from the pool of those employed to the pool of those not in the labor force. If the job itself is not destroyed, another person may move from unemployment to employment to fill it. If a construction worker's job ends with the first snowfall, that is a job destroyed. Simultaneous. ly, the worker may move from employed to un. employed or leave the labor force. On the other hand, he or she may move immediately into another job, perhaps one created in anticipation of the Christmas boom in retail sales, one that will be destroyed in January. Taking a wider view, an observer of the U.S. economy might notice that since the trough of the most recent recession, prominent employers have laid off thousands of workers-jobs destroyed-but more diffuse (and thus less visible) job creation has nevertheless raised overall employment by more than 3 million.

Standard measures of labor market developments condense all of these events into a single number, the net change in employment. Useful as they are, these statistics hide an interesting and potentially informative (though difficult to measure) dimension of labor market developments: the gross numbers of jobs created and destroyed and the gross movements of individuals into and out of employment. An employment increase of 10,000 by one of the usual measures may mean 10,000 hires and no job separations, or it may mean 500,000 hires and 490,000 separations. Clearly, the nature of economic forces underlying these two scenarios may be radically different. The first portrays an economy with stable, perhaps rigid, labor markets, while the second conveys a picture with much more activity. The U.S. economy turns out to be much more like the second scenario, with surprisingly high levels of job destruction and creation, particularly during recession and recovery periods, respectively.

This article introduces the ideas behind measurement of gross labor market flows, presents several such measures, including a new one, and outlines some of the ways these data may influence economists' views of macroeconomic events. The article first examines three sources of information on gross labor market flows. These are (1) establishment-level data assembled by Steven Davis and John Haltiwanger from the Census Bureau's Survey of Manufactures, (2) industry employment data from the Bureau of Labor Statistics' (BLS) Current Employment Statistics (CES) program toften called the estab- 
lishment survey, though information on individual establishments is not available from this source) and (3) household data extracted from the Current Population Survey (CPS). To prevent confusion with the establishment-level data from the Survey of Manufactures, the second data source (CES) will subsequently be termed industry data.

The Survey of Manufactures and industry data look at gross flows from the standpoint of employers, that is, from the demand side of the market. Measured gross job creation is the sum of increases in employment at those firms/ industries that experience increases. Measured job destruction instead sums decreases. The household data measure gross flows from the supply side of the labor market as the sum of individuals' movements into employment (gross job finding) and the sum of their movements out of employment (gross job separation).

After describing the gross flow data, the article turns to a discussion of ambiguities that can arise because of the interval between surveys or the choice of measurement unit (household, establishment of industry). The last two sections in the article note differences and similarities among the different gross flow measures and some implications of looking at labor market data in this way, especially the hypothesis that business cycles are driven by sectoral shifts.

\section{MANUFACTURING ESTABLISH. MENT DATA}

Davis and Haltiwanger (1990, 1992) have assembled and analyzed gross flow data from the Annual Survey of Manufactures undertaken by the Census Bureau. In 1977 the Survey of Manufactures covered approximately 19 percent of manufacturing establishments (including all establishments above a certain sizel and 76 per. cent of manufacturing employment. ${ }^{1}$

Davis and Haltiwanger's series for gross job creation and destruction rates are defined as the sum of the absolute values of employment changes in establishments with increasing and

IDavis and Haltiwanger (1990), p. 128. An establishment is defined as a single phystcal location. Thus, one firm may comprise several estabishments.

2To compensate for the stratified sampling design, establish ments are weighted by the inverse of their sampling probabilities. For a description of how births and deaths of establishments are handled, see Davis and Haltiwanger $(1990)$. decreasing employment, respectively, divided by total employment in sample establishments:

$$
\begin{aligned}
& J C_{t}=\frac{1}{E_{i}^{M}} \sum_{i=1}^{N_{t}} \delta_{i t}^{(+)} \Delta E_{i t} \\
& J D_{i}=\frac{1}{E_{t}^{M}} \sum_{i=1}^{N_{t}} \delta_{i t}^{(-1}\left(-\Delta E_{i t}\right),
\end{aligned}
$$

where $E_{i}^{m}$ is total employment in sample establishments, $E_{i t}$ is employment in establishment $i$, $N$ is the number of establishments in the sample, $\delta_{i t}^{(+)}=1$ if $\Delta E_{i t}>0$ and 0 otherwise, and $d_{i t}^{r-j}=1$ if $\Delta E_{i t}<0$ and 0 otherwise. ${ }^{2}$

The series for job creation and destruction as calculated by Davis and Haltiwanger are shown in Figure $1{ }^{3}$ Davis and Haltiwanger draw attention to several features of these time series.

First, the magnitude of job creation and destruction is dramatic. Job creation and destruction average 5.4 percent and 5.6 percent, respective$\mathrm{ly}$, at a quarterly rate over the 1973-86 period. Second, there is a clear negative correlation be. tween creation and destruction during reces. sions. Third, job destruction accounts for much more of the movement in employment during recessions than does job creation. Fourth, at no time is either job creation of job destruction near zero; simultaneous creation and destruction is the rule without exception.

\section{Limitations of the Manufacturing Establishment Data}

Though establishment-level data have important advantages for measuring gross flows, this data source also suffers from serious limitations. The most obvious is that it is restricted to manufacturing, which accounted for only about 17 percent of employment in 1992 (down from 26 percent at the start of the Davis and Haltiwanger sample in 1972). Second, these data are available only with a substantial lag, and the raw data are not publicly available.

In principle an establishment could incorrectly report employment levels in a quarter, thus generating spurious job creation or destruction

These series are updated versions of the POS and NEG series used in Davis and Haltiwanger (1990). The data were kindly provided by John Haltiwanger. 


\section{Figure 1 \\ Rates of Gross Job Creation and Destruction in Manufacturing (Davis and Haltiwanger data)}

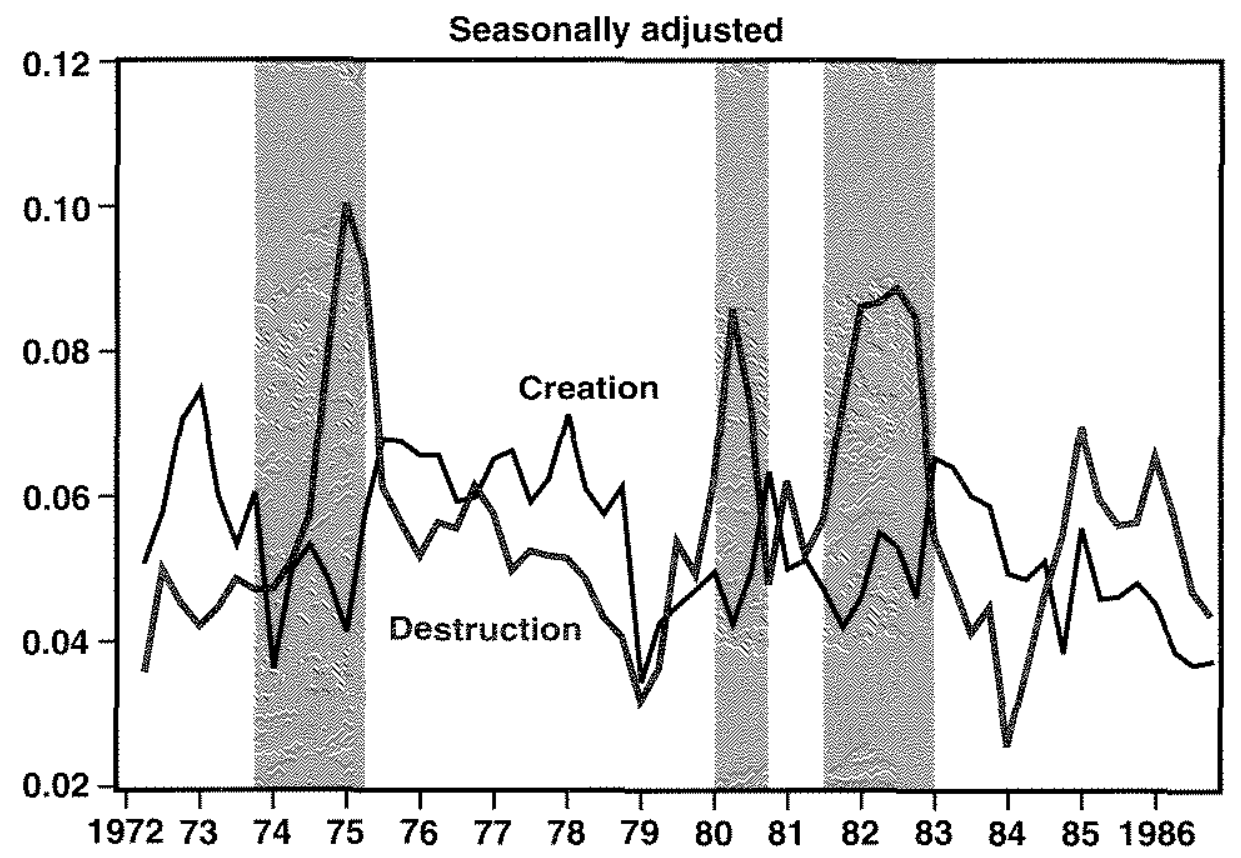

Shaded areas represent recessions.

lor both if the error were subsequently correct ed). This kind of classification error plagues the household data but seems unlikely to be a serious problem here, though there is no evidence avalable on the question.

\section{INDUSTPY DATA}

A second approach to measuring gross job creation and destruction, developed for this article, is similar to Davis and Haltiwanger's, but uses a breakdown of employment by industry based on the monthly BLS Current Employment Statistics (CES) survey. While there are disadvantages to basing gross flow measures on industry-level data (particularly the netting of job creation and destruction within industries), this approach offer's several significant advan* tages: (1) industry coverage can be quite comprehensive; (2) the data are publicly avalable; and (3) the data are avalable monthly without a major publication lag.
The raw data are employment levels in sever. al hundred industries in the private nonfarm sector of the economy. The CES sample current. ly covers more than 370,000 establishments, including all firms with more than 250 employees and a subset of smaller firms. ${ }^{4}$ These data are benchmarked annually using yet more comprehensive information, The CES sample excludes agricultural workers, unpaid family workers, domestic workers in private homes, and selfemployed persons (all of whom are included in the household data described in the next sec. tion). To focus on job creation and destruction driven primarily by market forces, the data used for this paper also exclude government workers, though the CES sample includes them. People who hold jobs at more than one establishment will be counted more than once. Though the data are collected from individual establishments, only industry totals are publicly avallable.

In a month $t$ when there is no change in the industrial classification (most months), the

4A detailed description of the CES program can be found in the BLS Handbook of Methods. Each issue of Employment and Earnings contains an abbreviated description in the

"Explanatory Notes" section. 
gross job creation and destruction rates are defined analogously to Davis and Haltiwanger's measures:

$J C_{t}=\frac{1}{E_{i}} \sum_{i=1}^{N_{1}} \delta_{i t}^{(+)} \Delta E_{i t}$

$J_{i}=\frac{1}{E_{i}} \sum_{i=1}^{N_{i}} \delta_{i t}^{(n)}\left(-\Delta E_{i t}\right)^{\prime}$

where $E_{\mathrm{f}}$ is total employment in these industries and $E_{i t}$ is employment in industry $i$. The construction of job creation and destruction series using CES data is complicated by the evolving classification of industries. At various times the standard industrial classification (SIC) used by BLS to allocate employment among industries is revised. In general, the revision results in a finer breakdown of industries already included, but sometimes it adds coverage of entirely new industries. ${ }^{5}$ The job creation and destruction series are constructed so that the breadth of industrial coverage does not change from the first period to the last. A finer breakdown within a larger industry is exploited, however. An adjustment at the "birth" of a new three- or four-digit industry accounts for the fact that the start of data on the industry does not indicate job creation, but reclassification. Since new three- and four-digit industries are generally created to subdivide growing industries, this procedure tends to limit the extent of netting of job creation and destruction within industries. The procedure followed in periods when a finer breakdown of an industry appears in the data is described in the appendix.

Figure 2 shows rates of job creation and destruction using a base of two-digit industries for which data are available since 1947. Almost all of these are manufacturing industries, so this series is dominated by manufacturing, which has been a declining share of total employment for several decades. Since the breadth of industrial coverage increases substantially in 1958 and 1972, Figure 3 shows results of the same calculations on industries for which data are available in 1972. Neither Figure 2 nor Figure 3 is affected in a substantial way by excluding government from the base of industries. The data plotted in Figures 2 and 3 are seasonally adjusted using the X-11 procedure and further smoothed using a five-month centered moving average.

The industries in the 1972 base are a comprehensive cross-section of the nonfarm business sector. In January 1972, employment was 59.2 million for all private nonfarm payrolls, only 23.5 million ( 39.7 percent of the total) for the 1947 base of industries, but 57.8 million 97.6 percent) for the 1972 base. By June 1993, total employment was 91.3 million for all private nonfarm payrolls, 23.3 million (25.5 percent) in the 1947 base and 87.3 million (95.6 percent) for the 1972 base.

One notable aspect of Figures 2 and 3 is that job creation rates are substantially higher during the 1980 s using the 1972 base than using the 1947 base, whereas job destruction rates do not differ much between the two bases. This is largely because many of the industries that are excluded from the 1947 base are those which experienced rapid growth during the 1980s relative to other industries. Most segments of construction, transportation, communications, utilities, trade, insurance, real estate and serv. ices (including medicall that are included in the 1972 base are not in the 1947 base.

These gross flow measures based on industry data also show a pronounced cyclical pattern. Job destruction still dominates cyclical movements in total employment, though creation appears more cyclical in the industry measures than in the Davis and Haltiwanger measure.

The most recent recession was marked by unusually small changes in job creation and destruction rates (see Figure 3 ). The job destruction rate rose and fell, but by far less than in recent recessions. This surprising fact is discussed more extensively later in this article. The job

\footnotetext{
sFor example, starting with 1958 data, the industrial machinery and equipment (SIC 35 ) category is broken down into engines and turbines (SIC 351), construction and related machinery (SIC 353 ) and so on. In 1972, industry 353 was itself subdivided into construction machinery (SIC 3531) and mining machinery (SIC 3532). Also in 1972, the remainder of industry 35 was further subdivided by addition of farm and garden machinery (SIC 352), general industrial machinery (SIC 356), and miscellaneous industrial and commercial machinery (SIC 359 ).
} 
Figure 2

Rates of Gross Job Creation and Destruction, 1947 Base

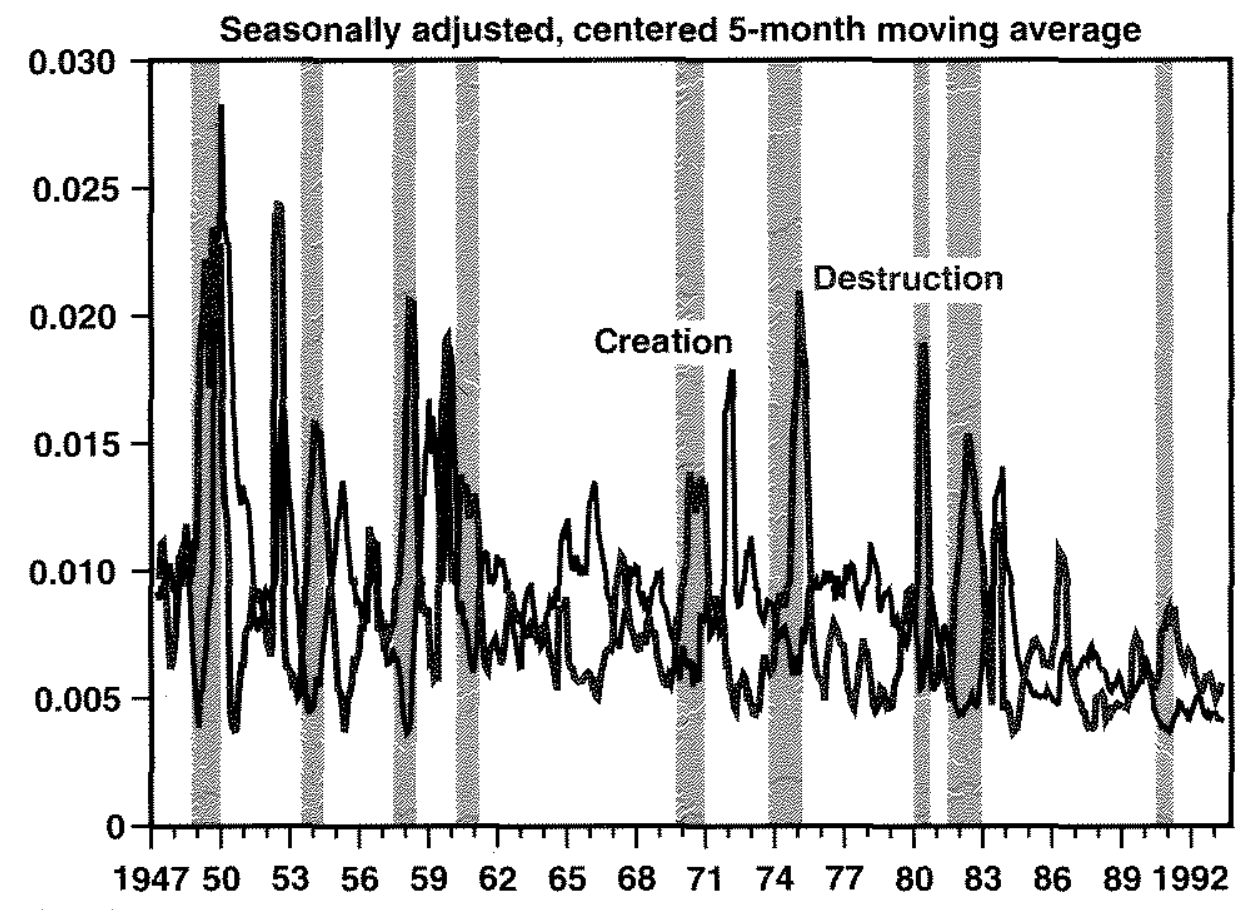

Shaded areas represent recessions.

Figure 3

Rates of Gross Job Creation and Destruction, 1972 Base

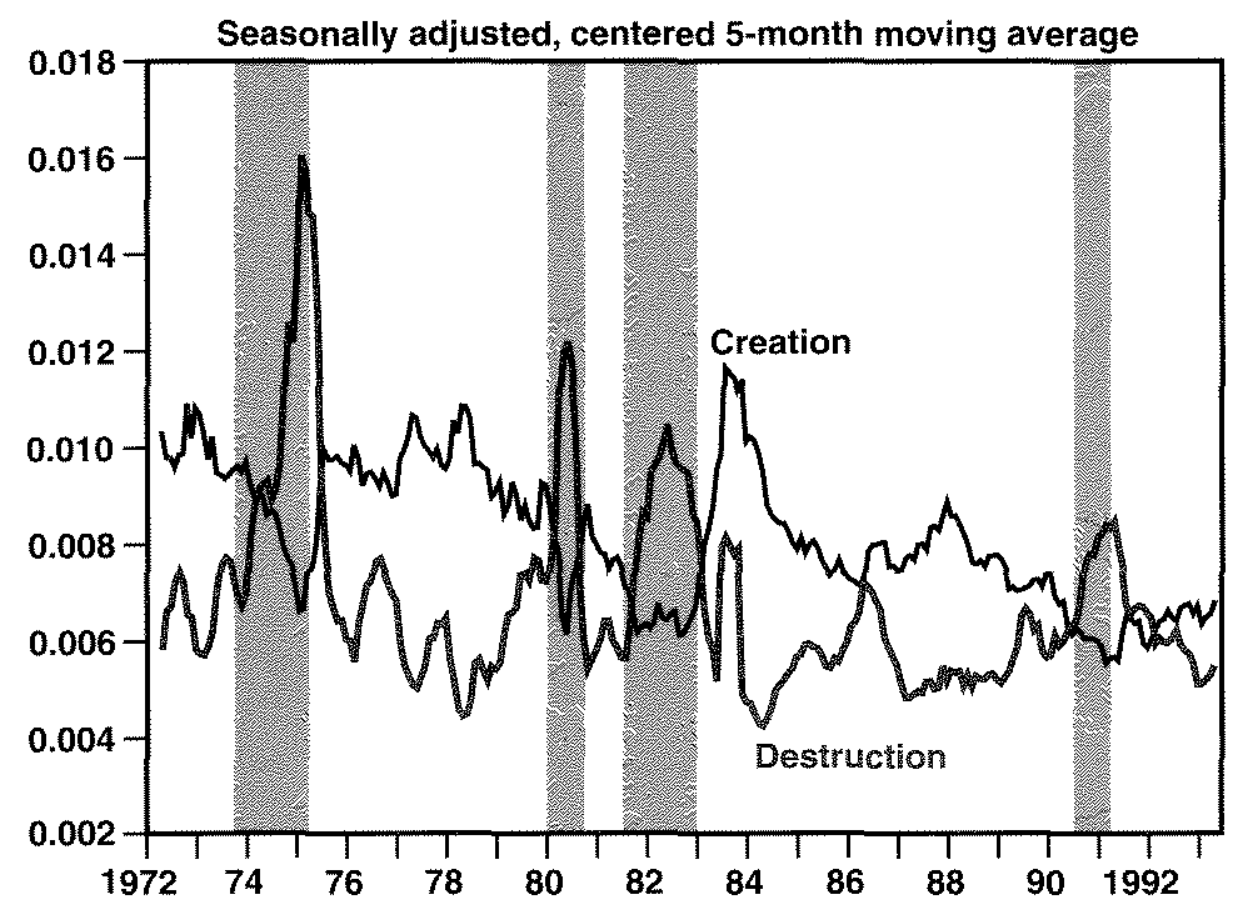

Shaded areas represent recessions. 
Table 1

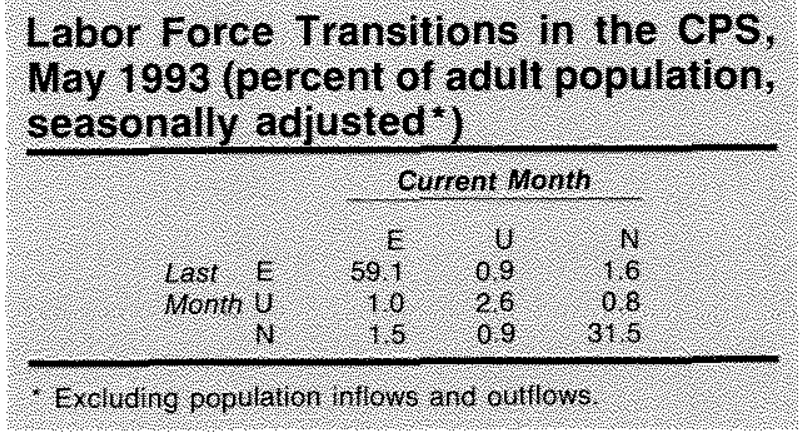

creation rate showed no sharp increase around the time of the trough as it did in previous recessions. Shortly before the trough of the 1990-91 recession the job creation rate reached its lowest level since the 1950s. The earlier low points were the result of sharp downward swings, however, while the recent low resulted from a small downward swing that followed a decade-long downward trend in the rate. In ad dition, job creation and destruction remained close together following the March 1991 trough, illustrating the slow growth of employment after the recession.

\section{Limitations of Industry-Based Data}

The most compelling problem with this approach to gross flows is the large measurement unit (an industry). To the extent that some firms within an industry increase employment during the same month that other firms decrease employment, we get net rather than gross flows. Obviously, this is far more likely to be a serious problem when the measurement unit is an entire industry rather than a single establishment or household. As industries grow, this problem becomes more severe. This effect is largely offset, however, as industry detail increases over time. A more extensive discussion of the netting issue is deferred until a later section.

In principle, these data, like the Davis and Haltiwanger data, are subject to classification er- rors. An establishment could incorrectly report employment levels in one month, thus generating spurious job creation or destruction for both if the error were subsequently corrected). If these errors are not correlated within an industry, they may cancel out, but there is no evidence avatable on this question. ${ }^{6}$

\section{HOUSEYHOD DATA}

Each month the Current Population Survey (CPS) collects employment data from a sample of about 60,000 households, obtaining information on about 113,000 persons 16 years of age or older (about 0.6 percent of this population). The survey attempts to establish whether each member of the household was employed (E), unemployed (U), or not in the labor force (N) during the previous week. Though there are some refinements to deal with special situations, broadly speaking an individual who worked during the survey week is counted as employed, and one who did not work but was actively looking for work is counted as unemployed. Otherwise the individual is not in the labor force.

Each household is in the sample for a total of eight months in two separated segments of four consecutive months. The households are divided into overlapping rotation groups so that about 75 percent of the households are the same in adjacent months. ${ }^{7}$ These continuing households make it possible to track changes in the labor market status of many individuals. The information from each household is weighted to produce estimates of economy-wide flows. ${ }^{8}$

The April 1993 to May 1993 flows among E, U and $\mathrm{N}$ and the relative sizes of the $\mathrm{E}, \mathrm{U}$ and $\mathrm{N}$ pools are shown in Table 1 and Figure 4 . The relative magnitudes of these flows are fairly typical. As Table 1 indicates, most of the adult population either stays employed (59.1 percent) or out of the labor force (31.5 percent) from month to month. The $\mathrm{E}$ to $\mathrm{N}(3.2$ million) and $\mathrm{N}$ to E (3.0 million) flows shown in Figure 4 are the largest in absolute magnitude, but the $U$ to $\mathrm{E}(2.0$ million $)$ and $\mathrm{U}$ to $\mathrm{N}(1.5$ million $)$ flows are

Guchitelle (1993) and Kreisler (1993) describe a recent incident that ilustrates the vulnerability of data from establishments to reporting errors.

7US. Department of Labor, Bureau of Labor Statistics, BLS Handbook of Methods, Bufletin 2414, September 1992, pp. $5-6$. The actual proportion of households will be somewhat smaller than 75 percent for reasons discussed later.

BThe number of individuals unemployed five weeks or less and initial unemployment claims have also been used as crude measufes of the gross flow of workers into unemployment. The former would measure movements from both employment and out of the labor force. The latter is tied to movements from employment to unemployment. 
Figure 4

Gross Flows in the Current Population Survey, May 1993

Millions, seasonally adjusted

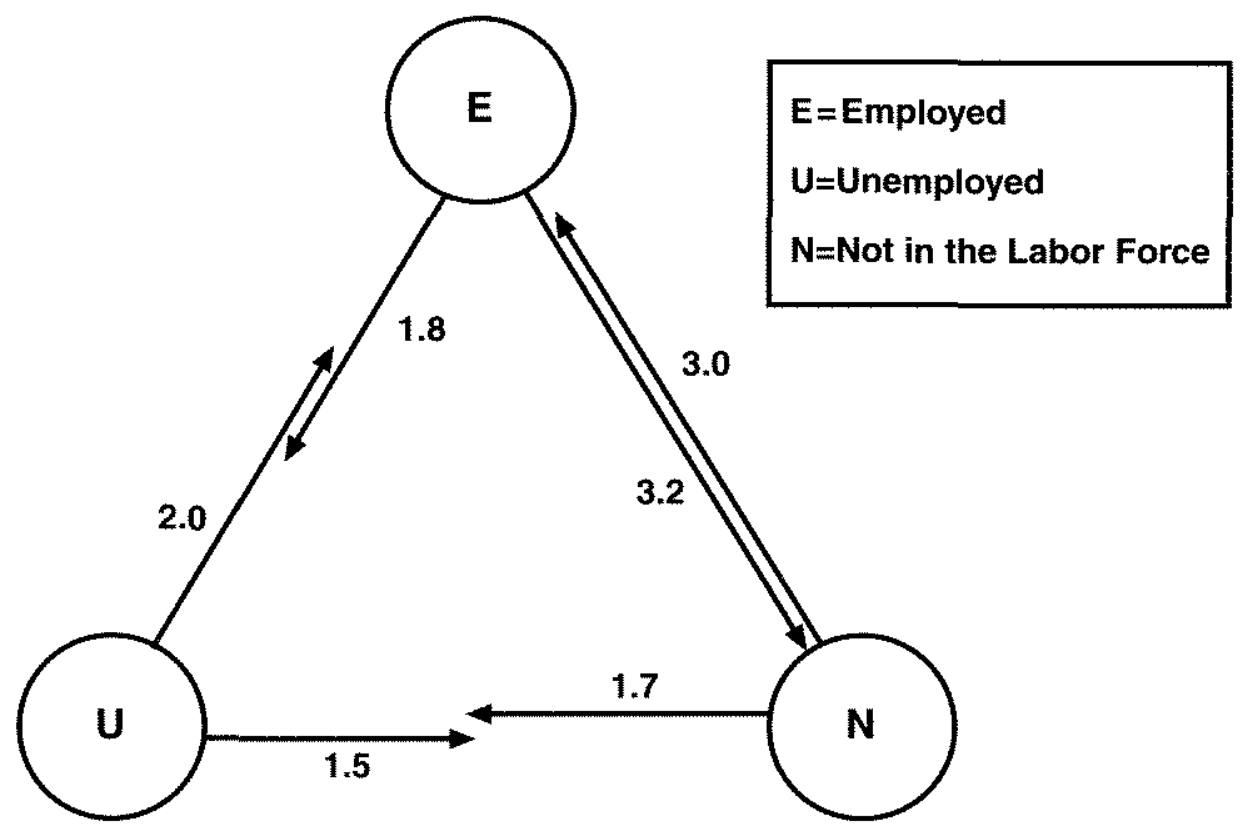

Status of Working Age Population, May 1993

Millions, seasonally adjusted

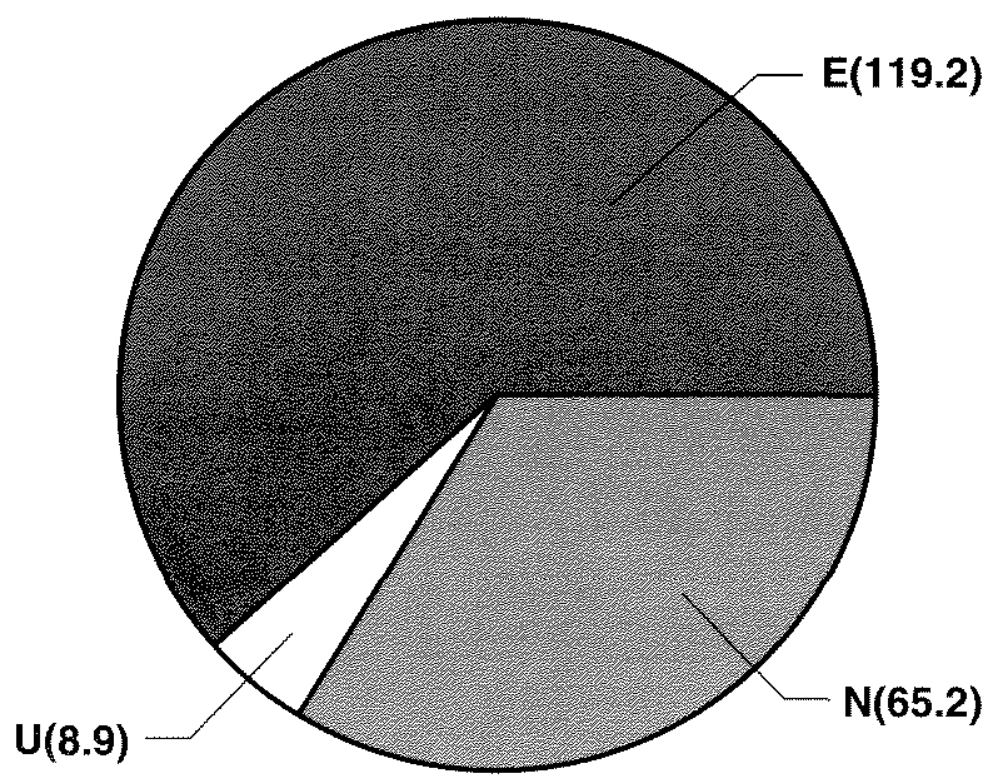


much larger in relation to the size of the group from which they are drawn. Table 1 illustrates this: More than two-thirds as many people left unemployment $(1.0+0.8=1.8$ percent $)$ as remained unemployed ( 2.6 percent). On the other hand, less than 5 percent as many people left employment as stayed employed (2.5 percent compared with 59.1 percent).

Figure 5 shows gross job finding the sum of $\mathrm{U}$ to $\mathrm{E}$ and $\mathrm{N}$ to $\mathrm{E}$ movements) and gross job separation (the sum of $\mathrm{E}$ to $\mathrm{U}$ and $\mathrm{E}$ to $\mathrm{N}$ ), as a proportion of total employment, from mid-1968 to mid-1993.9 The terms job finding and job separation will be used throughout in connection with the household data to emphasize that these data are based on worker movements rather than the creation or destruction of specific jobs. Though job creation and finding are closely bound together, as are job destruction and separation, the measured gross flows are based on fundamentally different approaches.

The data in Figure 5 are seasonally adjusted using the $X-11$ procedure and are further smoothed using a five-month centered moving average.

These data show a striking cyclical pattern similar to the demand-side measures. The net drop in employment during recessions the usual way of viewing employment) is clearly dominated by job separations, just as job destruction dominates in the establishment and industry gross flow measures. In four of the five recessions shown, job finding actually increases during the recession. A second prominent feature of Figure 5 is the downward trend in gross job finding and separation rates that starts around 1984. This may be accounted for by changes in the demographic structure of the working-age population but there are difficulties with this interpretation. Further discussion is deferred until the end of the article.

\section{Limitations of CPS Gross Flows}

Several serious problems with the CPS gross flow data have limited their usefulness. The least serious is sampling error. Even though the CPS sample is quite large, the number of transitions among states is relatively small; most of those reported as E/U/N this month will be iden. tically reported next month (see Table 1). "This means that the standard error around this estimate of the true number of people changing status will be large in proportion to the num ber. The sampling error, while comparatively large, is zero on average, so it does not bias the estimated flows.

The second problem is missing observations. The sampling unit for the CPS is actually a residence rather than a household; the interviewers return to the same address for four consecutive months. If the household moves, it drops from the sample and is replaced by the household living at that address, if any. If an adult moves into or out of the household, the individual ap. pears in or disappears from the sample. About 7.5 percent of individuals in particular residences in the previous month cannot be found in data for the current month. In addition, about 7.5 percent of individuals in particular residences in the current month's data were not recorded in the previous month's data. ${ }^{10} \mathrm{In}$ dividuals who move are probably more likely to change labor force status than those who do not. This would bias the gross flows downward. Abowd and Zellner estimated gross flows corrected for nonrandom missing data and found that corrected flows into employment were 22 percent higher and corrected flows out of em. ployment were 16 percent higher than unadjusted flows. ${ }^{11}$

The third problem, classification error, has generated the most attention. If an employed individual is classified correctly in month 1 , incorrectly as unemployed in month 2 , and correctly in month 3 , with no change in true status, two spurious transitions ( $\mathrm{E}$ to $\mathrm{U}$ and $\mathrm{U}$ to $\mathrm{E}$ ) have been recorded. These response errors arise partly because of the design of the survey. One individual from each household answers questions about every adult in the household, but this is not necessarily the same individual each month. Different respondents may answer questions about the labor force status of household members in different ways. In addition, there is some ambiguity about where the lines are drawn between employed, unemployed and not in the labor force. The line between unemployed and not in the labor force is particularly fuzzy (though not relevant for Figure 5).

\footnotetext{
9various problems with the CPS gross flow data greatly distort the relationship between job finding and job separation rates in Figure 5 . These problems are discussed extensively in the next subsection.
}

\footnotetext{
10Abowd and Zellner (1985), p. 254.

$1:$ Abowd and Zenlner, Table 3, p. 264.
} 
Figure 5

Rates of Gross Job Finding and Separation from the Current Population Survey

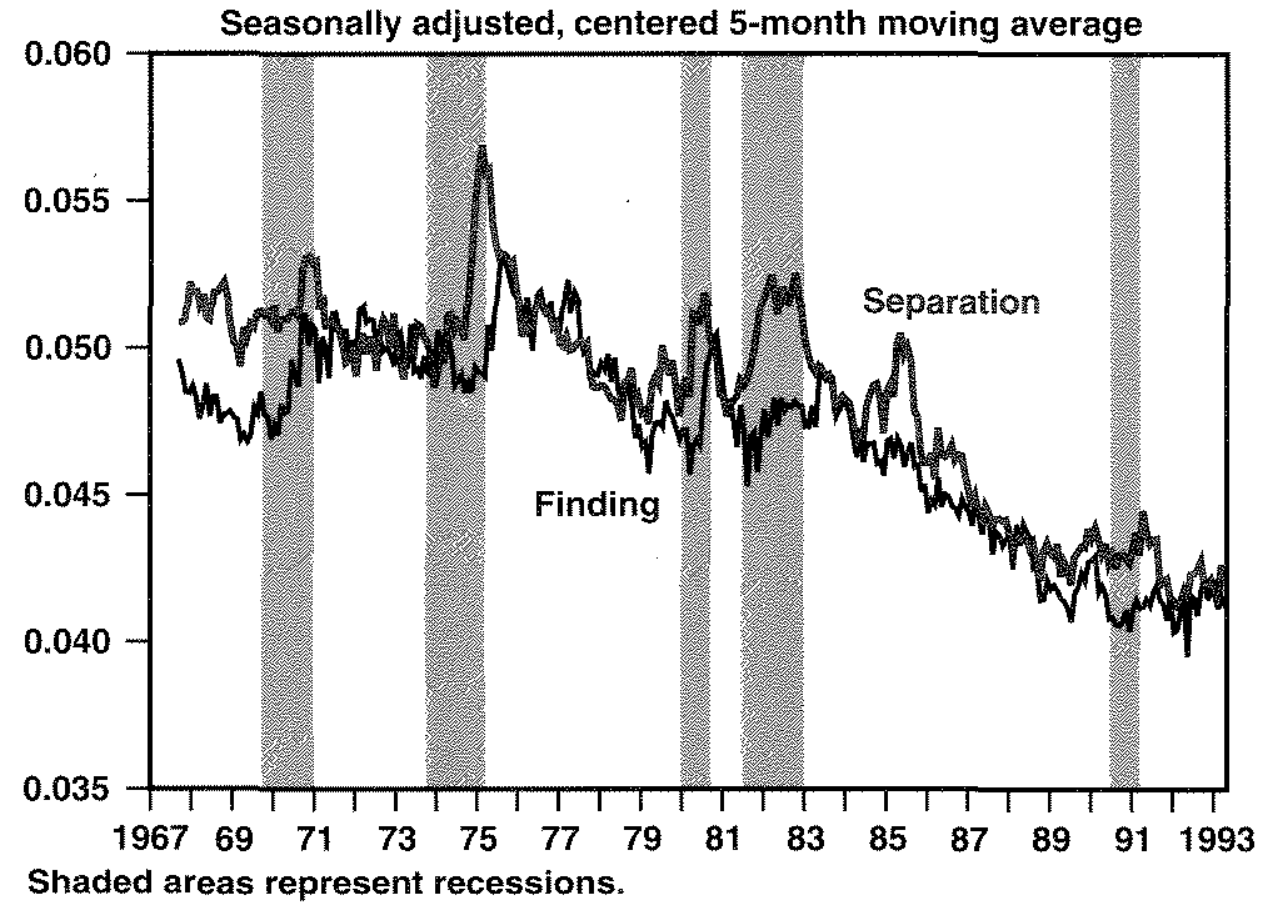

Because actual transitions are relatively rare, a small probability of classification error can generate errors in the gross flow data that are quite large in proportion to the true flows. In January 1993, for example, the data indicate that 61.5 percent of the adult population was employed. If 2.3 percent of employed workers incor'ectly report their status as not employed (the estimate reported by Poterba and Summers in table 3), then 1.41 percent of the sample repont a spurious transition out of employment. ${ }^{12}$ Only about 3 percent of the sample actualy reports such a transition in January 1993 , so 46 percent $(1.41 / 3)$ of the gross flow out of employment would be spurious under this scenario.

There have been several attempts, including those by Abowd and Zellner (1985) and Poterba and Summers (1986), to correct this upward bias in gross flow data using reinterview data collected by BLS as part of a quality control program. A small fraction of the original sample is surveyed a second time by experienced personnel, most of whom are asked to $\mathrm{I}^{2} \mathrm{y}$ to reconcile differences between the first and second interviews. Reinterview data are assumed to be correct and are used to estimate the probabilities of classification error for different demographic groups. These estimates are then used to correct the gross flow data. Poterba and Summers (1986) adjust both job finding and job separation downward by more than 60 percent for the 1977-82 period. Abowd and Zellner (1985) adjust the same flows downward by more than 25 percent.

This approach is not wholly satisfactory, however, for at least two reasons. First, two studies taking similar approaches to the problem

\footnotetext{
12 This example assumes that the worker's status was correctly recorded in the previous month. Using that information, if it were available, would lower the error rate. However, it also ignores the offsetting possibility that people who were incorrectly recorded as employed last month are now correctly recorded, thus generating a further spurious flow out of employment.
} 
Figure 6

Change in Household Employment:

Actual vs. Gross Flows

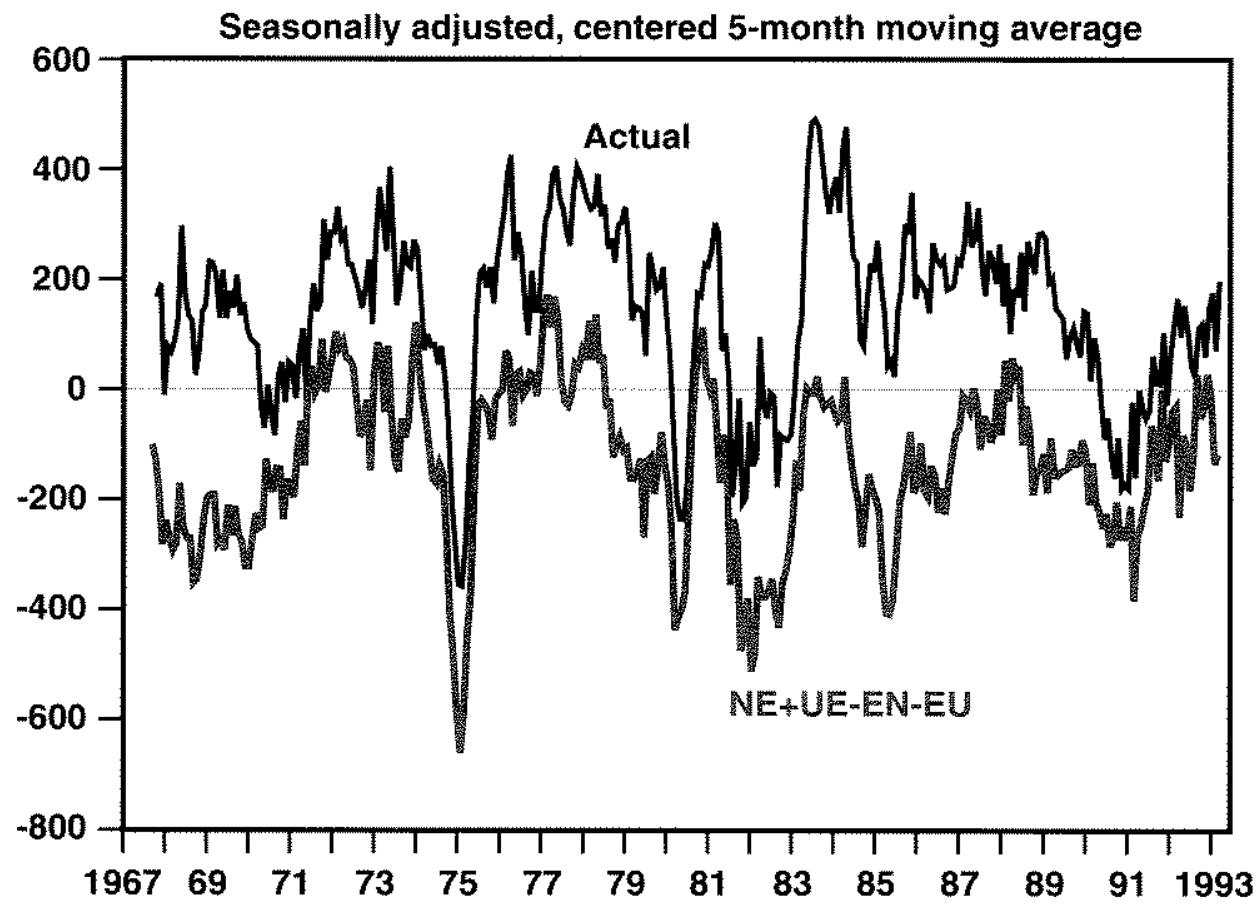

come up with adjustments that differ widely, and neither is clearly superior. Second, the reinterview program does not sample randomly (from the entire CPS sample), but rather concentrates attention on interviews that are prone to егто (for example, because the original interviewer is new to the job). This implies that the reinterview data are likely to exaggerate the extent of classification error.

An idea of the overall seriousness of the problems with CPS gross flow data can be gleaned from Figure 6, which compares the change in household employment estimated in the usual way with the difference between flows into and out of employment. The former is based on the change in the number of people in the CPS who report that they are employed, whereas the latter is based only on the responses of people who were surveyed in consecutive months and reported a change in employment status. In principle, the two should match quite closely, but the gross flows substantially understate employment growth over the entire sample period. This situation may improve significantly when a revised CPS is implemented in January 1994.

\section{HOW GPOSS APE GPOSS MEASURES?}

Because the subject of this article is gross employment flows, an important concern is the extent to which any particular measure of gross flows really measures gross rather than net flows. This issue arises on both the time and cross-section dimensions of the data.

Netting occurs intertemporally if, for example, an individual reports working in two consecutive surveys but was unemployed between the two reports. Similarly, a firm may have laid off and rehired workers from one quarterly report to the next. Obviously, this intertemporal netting will be more important the longer the interval between observations on a measurement unit. The household and industry measures are based on monthly data, whereas the Davis and Haltiwanger data are based on quarterly information.

Netting also occurs in the cross-section dimension when the measurement unit is larger than a single worker, A firm may hire some workers and fire others within the observation interval. An industry may be a mix of firms that are 
increasing and firms that are decreasing employ. ment (as well as firms that do both within the period).

Finally, since the degree of industry detail differs between sectors, with manufacturing employment by far the most finely subdivided, the degree of intraindustry netting almost certainly varies systematically across sectors.

Since there is an additional layer of netting involved in using industry gross flow data, it is important to understand the relationship be tween establishment- and industry-tevel variation in employment. Figure 7 compares the Davis and Haltiwanger series on job creation and destruction in manufacturing labeled establishment data) with series based on industry em* ployment data for manufacturing industries and using employment changes between the months of the Survey of Manufactures (February, May, August and November). These series differ mainy because they use different units of measurement (establishment vs. industry), although they are also based on different survey methodology. Two features of the comparison stand out. First, the profiles of the series are quite similar; the larger peaks and troughs coincide and have roughly the same size in both series, though the similarity is less apparent for job creation. "The same is true for seasonally unadjusted data (not shown). Second, the Davis and Hatiwanger series are substantially higher than the industry series. A large share of this gap is gross job creation or destruction that nets out when the unit of measurement is the industry. A closer look at the gap reveals that it has no pronounced trend and is not noticeably cyclical, suggesting that most of the job creation and destruction that disappears in this way using the industry series may not be of great interest from a macroeconomic perspective.

\section{CONMON AND CONTRATICTORE FEATUTHS}

\section{Magritudes}

Though the magnitudes of the three gross flow measures differ for many reasons, some informative and some spurious, all three measures are strikingly high. Davis and Haltiwanger's manufacturing establishment data show, for ex. ample, 5 and 7 percent rates of creation and destruction for the first quarter of 1986. The industry-based (1972 base) data indicate job cre ation and destruction rates of about 2 percent (with or without government) for the same quarter. The household data indicate that job finding and separation rates were about 14 percent each for the same quarter ${ }^{13}$ In addition, there are dramatic seasonal swings in these series (see the next section), so during the year the rates can be much higher than the average. Even the smallest of these magnitudes implies a labor market in which a great deal of activity takes place even when overall employment is not changing. There is evidence that European countries experience gross flows that are the same order of magnitude. ${ }^{14}$

The household data (Figure 5) show a sharp downward trend in both job finding and separation rates, starting around 1984. Total job find" ing and separation levels (not shown) have a clear upward trend to this point and no appar. ent trend afterwards. There is a plausible demographic explanation for the downward trend in the household data: Workers in their $30 \mathrm{~s}, 40 \mathrm{~s}$ and 50 s have lower rates of job separation and job finding. The baby-boom generation started to enter these years of stable labor force participation and job attachment in the early 1980s, and this increase in the proportion of workers with lower finding and separation rates would therefore depress the overall levels of gross job finding and separation.

The puzzle remains, however. This demographic hypothesis should also apply to the industry data because private payroll employment (from the CES) and household employment (from the CPS) show similar trends over time. The 1972 industry base includes almost all private payroll employment. However, the downward trend in job creation (industry data, 1972 base) is weaker than that in job finding (CPS data) and there is no downward trend in job destruction comparable to that in job separations. The main coverage differences between the CPS and CES employment series are (1) the CES excludes agricultural workers, self-employed workers and several smaller categories and (2) the CES data will record individuals with more than one job in the nonfarm payroll sector

\footnotetext{
${ }^{13}$ Adding together monthly job finding and separation rates to get quarterly rates (as was done here) is somewhat misleading since it is likely that many of the same people are moving repeatedly into and out of employment.

14Burda and Wyplosz (1990).
} 
Figure 7

Rates of Job Creation in Manufacturing

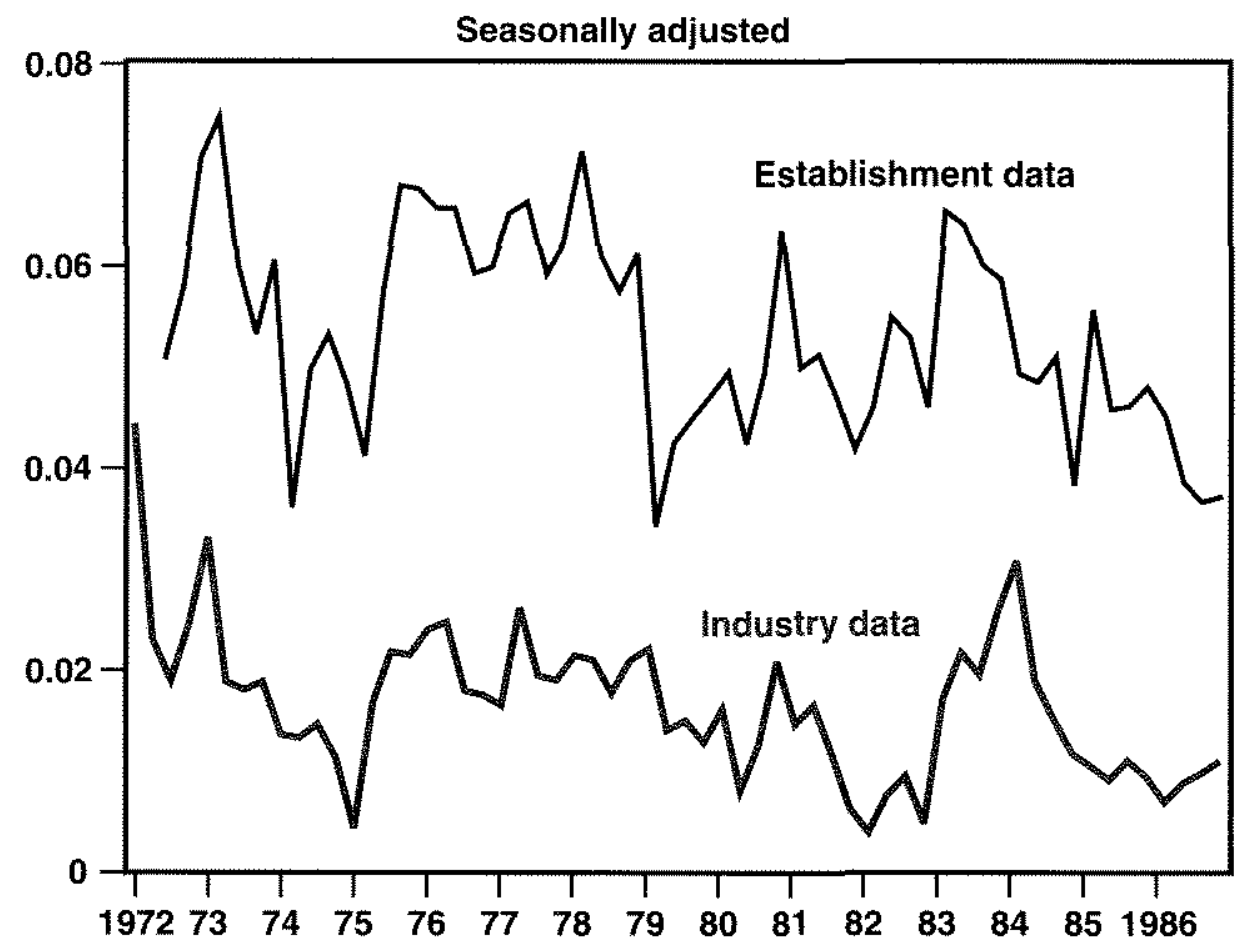

Rates of Job Destruction in Manufacturing

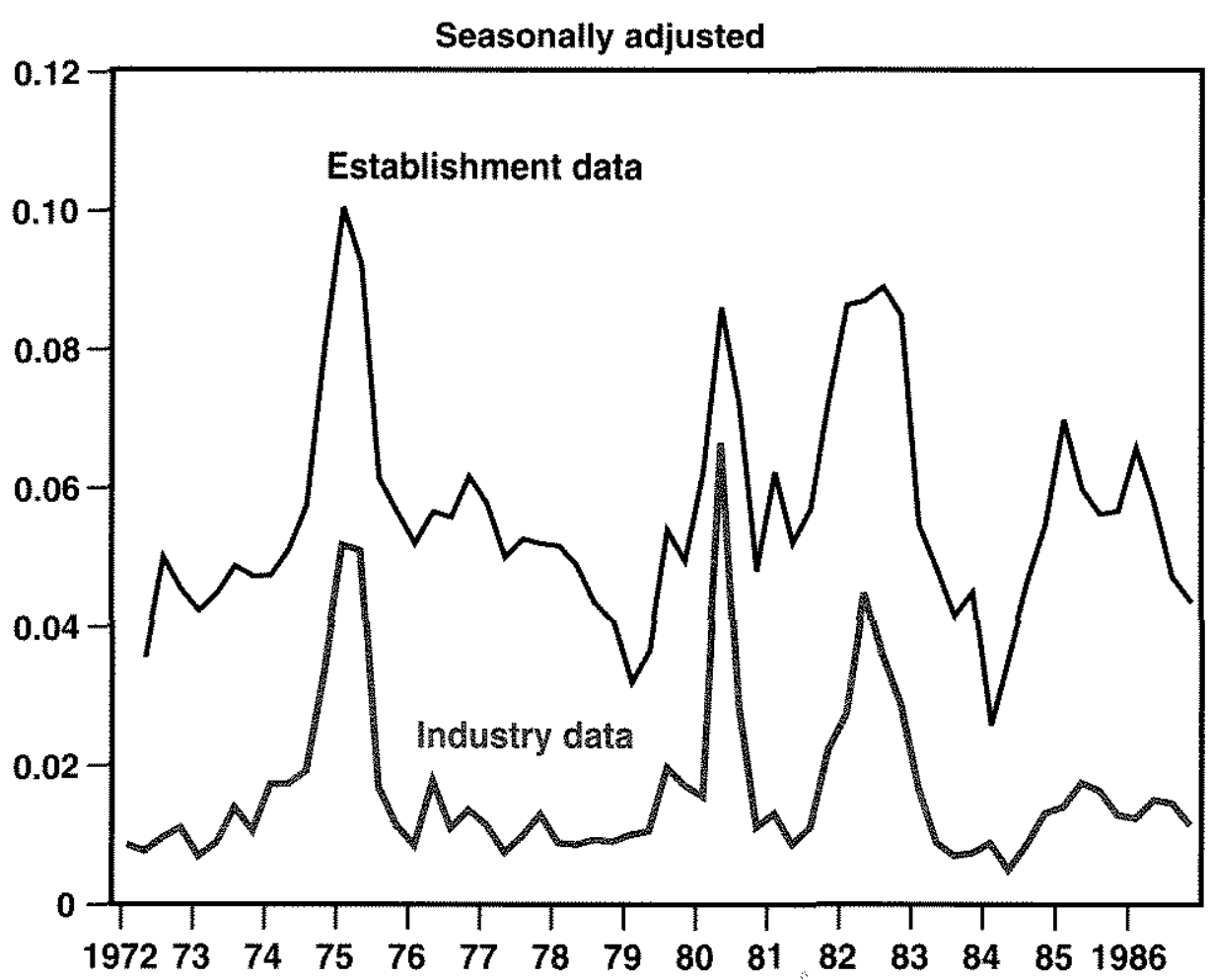


more than once. Neither of these seems likely to account for such a large difference in trends during the 1980s. The industry job creation and destruction data shown in Figures 2 and 3 do not include government workers, but the trends do not change when government workers are included.

\section{Seasonal Movements}

Not surprisingly, there are extremely pronounced seasonal patterns in the gross flow measures. The 1992 seasonal patterns estimated by the $\mathrm{X}-11$ seasonal adjustment procedure for the household and industry series (1972 base) are shown in Figure 8 . These are seasonal fac* tors for levels of creation and destruction (the data are not divided by total employment). They are the ratio of the unadjusted series to the seasonally adjusted series.

The industry data for job destruction show a dramatic seasonal peak in January, when the ratio of unadjusted to adjusted data is nearly 4 . The ratio of the highest to lowest seasonal factors for job destruction is nearly 15 , meaning that about 15 times as many jobs are destroyed in January on average as in April. The ratio is about 7.5 for job creation, with the high and low months being June and January.

Seasonal movements in job finding and separation are also quite significant, though the scaling of Figure 8 hides this. Seasonal factors in 1992 range from 0.8 to 1.2 for job finding levels and from 0.8 to 1.3 for job separations, ${ }^{15} \mathrm{By}$ contrast, seasonal factors for total civilian employment are only about one-tenth of this size 0.98 to 1.02).

Figure 8 highlights the fact that the seasonal fluctuations in the CPS gross flows data have much smaller amplitude than those in the industry data. The different underlying data sources are one reason for this. A worker who moves immediately from one seasonal job to another is not unemployed between the jobs, but this movement can correspond to seasonal job destruction in the first industry and seasonal job creation in the second. Similarly, if a seasonal job is a second job for an individual, there is no change in his or her labor market status as recorded by the CPS when the job begins or ends. No gross flow is generated in the CPS data in either case, but a job is recorded as both created and destroyed in data based on employer's' payroll records. These are relatively infrequent occurrences, but because labor mar. ket transitions are also relatively rare, their relative importance is much greater in measuring gross flows than in measuring total employment.

\section{Cyclical Movements}

One common feature of all three approaches to measuring gross flows is that employment declines during recessions are dominated by rises in job destruction or separation. Job crea tion or finding rates usually begin to decline well before the business cycle peak. Similarly, job destruction or separation rates tend to begin rising before the official onset of a recession.

The timing of the business cycle peaks in job destruction and troughs in job creation is interesting in two respects. First, the two usually almost coincide in both the industry and establishment series. ${ }^{16}$ This does not occur in the CPS data. Second, the peak of job destruction/separation tends to occur toward the trough of the recession and never occurs at the peak.

The household and industry data both indicate that the $1990-91$ recession was characterm ized by much smaller movements in gross destruction/separation and creation/finding rates than earliex recessions. This suggests that highly visible downsizing efforts by firms are somewhat misleading for the economy as a whole;

\footnotetext{
15 Seasonal factors (1986) for the Davis and Haltiwanger manufacturing series range irom 0.9 to 1.3 for destruction and from 0.98 to 1.04 for creation. Part of the reason seasonal factors are smalier for the Davis and Hattwanger series is that they are quarterly, so some of the seasonal fluctuations have already been smoothed out.

${ }^{16}$ This regularity is even more pronounced in unsmoothed data. A very simple model of job creation would predict that creation and destruction should be (distorted) mirror images of each other. Suppose that the change in employment for a particular firm or industry is given by $g_{i t}=e_{t}+$ $u_{i}$, where $e_{t}$ is an aggregate shock and $u_{i}$ is a film/industry specific shock that does not depend on time. A decrease
}

in $e_{t}$ then shifts the distribution of $g_{f t}$ to the left, throwing some firms/industries from the job creation column to the job destruction column. Job creation falls and job destruction rises. 
Figure 8

1992 Seasonal Factors (NSA/SA) for Job Finding and Creation (1972 Base)

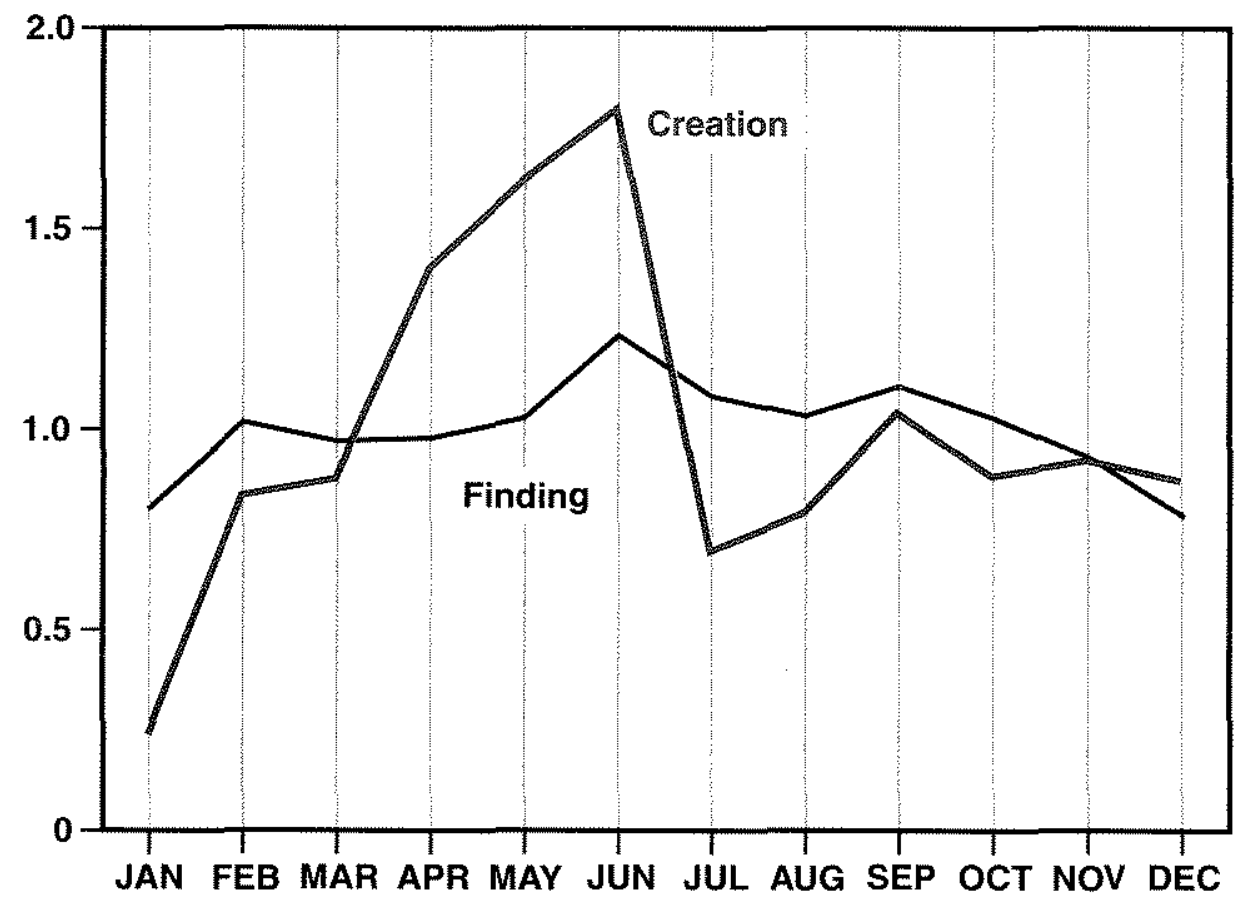

1992 Seasonal Factors (NSA/SA) for Job Separation and Destruction (1972 Base)

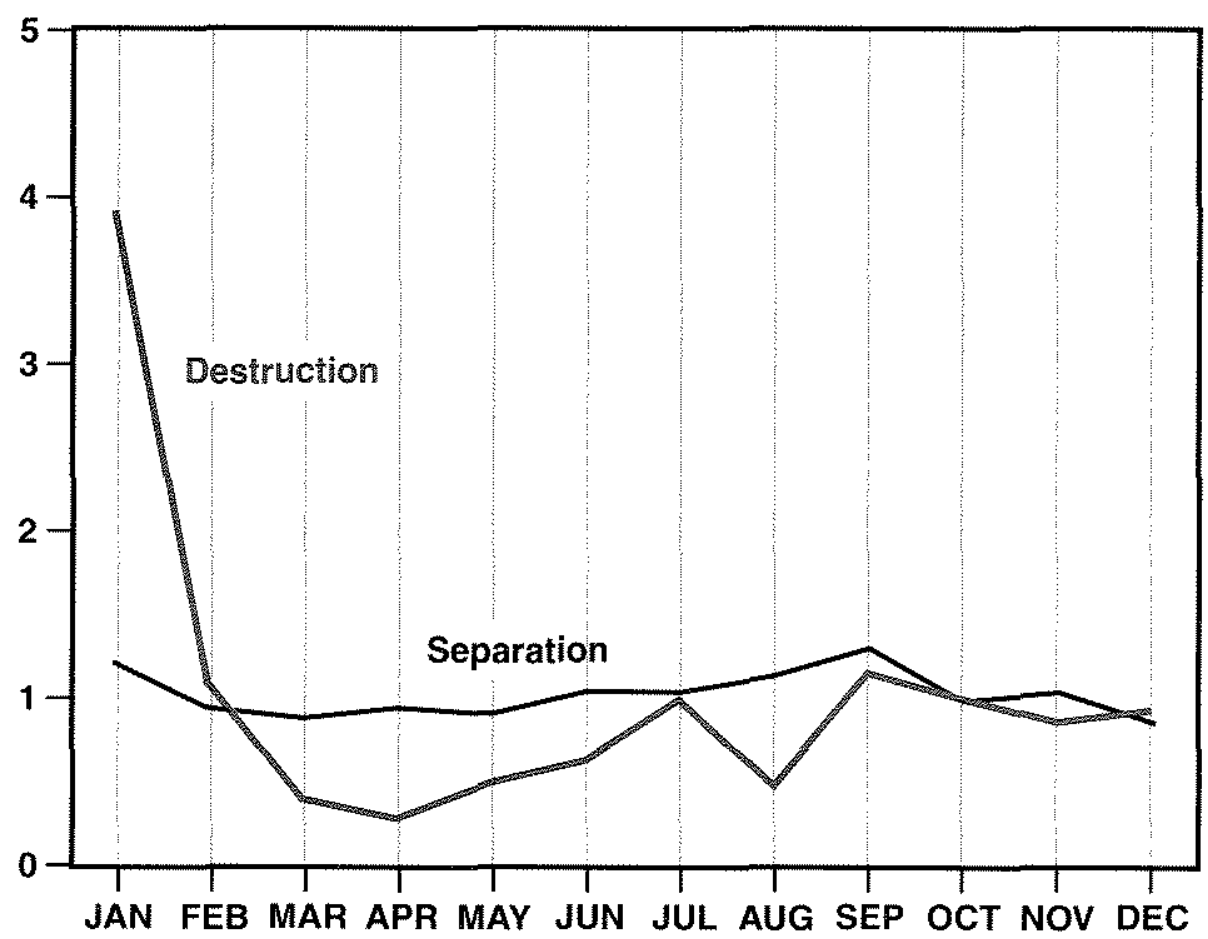


despite its visibility, job destruction was at sur. prisingly low levels during and after the 1990-91. recession. Two observations may help to reconcile perceptions with the job destruction statistics. First, BLS data indicate that an unusually large proportion of job losses during and after the 1990-91 recession were permanent rather than temporary layoffs (as reported by workers), increasing the perceived seriousness of the job destruction. Second, though job destruction in manufacturing did not reach particularly high levels during the recession, manufacturing has continued to shed jobs (that is, job destruc. tion exceeded job creation) in almost every month since the end of the recession. Manufacturing layoffs tend to be quite visible.

\section{MACPOECONOMIC APPLICATIONS}

Most macroeconomic analyses involving gross labor market flows have tried to assess what is often called the sectoral shift hypothesis. 'This hypothesis focuses on changes in the distribution of demand among sectors of the economy rather than on aggregate shocks. The macroeconomics literature typically assumes that business cycles are driven by aggregate shocks. Various sources of aggregate shocks have been hypothe. sized by macroeconomists-private expectations, monetary policy, oil price increases and technology shocks, to name a few. They share the common feature that all firms and individuals in the model are affected in relatively similar ways.

In a seminal paper, Lilien (1982) as gued that shocks to the distribution of demand among different sectors might account for a large portion of the variation in the level of economic activity. Adverse shocks to demand in specific: industries could cause dislocation of workers and other resources that would not flow smoothly into more productive pursuits. The adjustment period would be characterized by a decline in economic activity generally, and an increase in the unemployment rate in particu. lar, so there would be a positive relationship between cross-sectional variation in industry employment growth and the unemployment rate. Lilien estimated the relationship between the unemployment rate and a measure of the cross-sectional dispersion of employment growth in 11 broad industry groups. He found that more than half of the variation in the overall unemployment rate could be accounted for by variations in the cross-sectional dispersion of employment changes. ${ }^{17}$

Lilien's results have not been regarded as conclusive. Abraham and Katz (1986) pointed out that an increase in Lilien's measure of the crosssectional dispersion of employment growth could be induced by aggregate shocks, given plausible assumptions about industries' trend rates of growth and cyclical sensitivities. They argued that if the positive correlation between Lilien's dispersion measure and the unemployment rate were accounted for by sectoral shifts, there would also be an increase in job vacancies when the dispersion measure increased. Holding the overall level of aggregate demand fixed, some industries would be trying to hire as others' laid-off workers, causing a mismatch of workers and jobs and an increasing vacancy rate. If the business cycle is driven by aggregate demand, however, the relationship between dispersion and vacancy rates would be negative. They found a strong negative relationship, implying that aggregate demand fluctuations are the dominant source of variation in the unemployment rate, ${ }^{18}$

The sum of job creation and destruction series such as those by Davis and Haltiwanger or those produced using industry data can be used as a cross-sectional dispersion measure. For the Davis and Haltiwanger data:

$$
S U M_{1}=J C_{t}+J D_{i}=\frac{1}{E_{t}^{M}} \sum_{i=1}^{N_{t}}\left|\Delta E_{i t}\right|
$$

SUM increases when there is more variation in employment change in individual industries. Both SUM, and an analogous measure based on industry data move countercyclically since $J D$; tends to rise more than $J C_{i}$ falls during recessions.

To get more insight into what might drive changes in dispersion, equation (1) can be re. written in terms of growth rates:

17. Lilten (1982), p. 792.

18Abraham and Kalz wsed a normalized heip-wanted index to proxy tor a direct measure of vacancies in the United States. They found similar results in British data using a direct measure of vacancies. 
(2) $S U M_{t}=\sum_{i=1}^{N_{t}} \frac{E_{i t}}{E_{q}^{m}}\left|g_{i t}\right|$,

where $g_{i t}$ is the growth rate of employment in establishment $i$. The growth rate of establishment $i$ can be written as follows:

$$
g_{i t}=\tilde{g}_{i t}+g_{i}^{s}+g_{i}
$$

where $g_{t}$ is the average growth rate for all manufacturing establishments, $g_{i}^{s}$ is the average growth rate for industry or sector $s$ minus $g_{t^{\prime}}$ and $\tilde{g}_{i i}$ is the residual, or idiosyncratic, growth of this establishment.

Davis and Haltiwanger find that nearly all of the variation in $S U M$, over time can be attributed to the $\tilde{g}_{i l}$ component. For example, when the sectors indexed by $s$ correspond to two-digit industries (a relatively broad industrial classification), $\bar{g}_{u}$ accounts for 87.6 percent of the variation in $S U M_{t}$. Replacing $g_{i t}$ with $\tilde{g}_{i t}$ in (2) gives a dispersion measure $\widehat{S U M}_{t}$ that has average aggregate and industry growth rates removed. Davis and Haltiwanger find that $\widehat{S U M}_{1}$ is also countercyclical. They conclude, "We interpret these variance ratio results as a decisive rejection of the hypothesis that the normal pattern of sectoral responses to aggregate fluc. tuations can account for the significant time variation in $[S U M] \ldots$ The time variation in [SUM $]_{t}$ results overwhelmingly from time variation in the contribution of idiosyncratic effects." ${ }^{19}$

This empirical observation does not necessarily mean that shifts in industry demand, broadly defined, are not the source of much of the variation in $\overline{S U M}_{1}$ or $S U M_{t}$, however. The variance decomposition technique labels only variation common to all establishments as industry varia tion. In other words, only if employment grows at exactly the same rate in all establishments will the variance decomposition attribute all variation to industry shocks. Any assumption used to distinguish industry shocks from establishment shocks, however, will be to some extent arbitrary, and this particular assumption may not be the best way to think about industry shocks. In the 1970s and 1980s, for example, the U.S. steel industry shrank dramatically, largely as a result of international competition. This increasing international competition could reasonably be interpreted as an industry shock, but its effects clearly differed from one firm to another. Some firms disappeared altogether.

Rather than assuming, as Davis and Haltiwanger do, that all firms respond identically to an industry shock, we could assume that the industry shock hits the weakest firms hardest. 'This would imply that firms' responses to indus. try shocks are extremely heterogeneous-in other words, that firms have idiosyncratic responses to industry shocks rather than truly idiosyncratic shocks. It is easy to demonstrate that this assumption can dramatically change the results of a variance decomposition exercise. The new identifying assumption may be equally arbitrary but illustrates the sensitivity of variance decomposition exercises to the assumptions used to identify industry shocks. Another way to state this conclusion is that the idiosyncratic shock $\tilde{g}_{i t}$ as constructed by Davis and Haltiwanger is not necessarily independent of the fortunes of the industry.

Though the best way to isolate responses to industry or aggregate shocks is a topic that deserves further study, it is certainly clear from Davis and Haltiwanger's work that firms' responses to cyclical shocks vary dramatically even within industries. Understanding the size and sources of heterogeneity in firms' employ. ment responses may be critical to understanding the role of business cycles in the economy. Macroeconomic models that assume firms' responses to shocks are homogeneous within industries will not capture any of the possible ramifications of this heterogeneity.

Dispersion $\left(S U M_{\mathrm{f}}\right)$ is not the only aspect of these data that should be of interest to macro. economists and, in fact, may be considerably less informative than its two halves, job creation and destruction. An important puzzle is the asymmetry between job creation and destruction in recessions, with changes in job destruction swamping those in job creation. Blanchard and Diamond (1990) argue that standard textbook models of entry and exit would predict the opposite. Existing firms exit (destroy jobs) only when they cannot cover variable costs, so exit is relatively insensitive to economic conditions. Potential entrants (job creators) must expect to cover total costs, including any fixed costs of entry. This implies that job creation will vary more than job destruction. Blanchard and Diamond speculate that differences in the costs

19Davis and Haltiwanger (1990), p. 138. 
of hiring and firing workers may lead to bunching of job destruction during recessions. They point out, however, that aggregate behavior is often not analogous to microeconomic behavior in these types of models, so they find the explanation only partly persuasive.

Blanchard and Diamond also observe that, since cyclical changes in employment are dominated by job destruction, Schumpeterian theories of business cycles seem to be ruled out. These theories argue that booms are brought about by waves of product innovations (com. puters, for example) that produce new jobs, whereas recessions occur when these waves recede. ${ }^{20}$ This kind of theory implies that employment changes will be dominated by changes in job creation.

Job creation and destruction data that are based on a comprehensive cross-section of the labor market, such as the industry-based series constructed for this paper, could prove useful in several areas. Although establishment-level data are clearly closer to ideal than industry data for the study of job creation and destruction, it is important to know what happens beyond manufacturing (where establishment data are available), as the experience of the most recent cycle indicates.

Comprehensive data on gross flows could also provide insight into the employment outcomes of a free-trade agreement. Opponents of such agreements argue that jobs will be lost. Proponents argue that while jobs will be lost, there will be a net gain in employment. Little is known, however, about the patterns of job gains and losses surrounding such agreements. If there is a net employment gain, as most economists would predict, are the corresponding consequences for job creation and destruction of a comparable or greater order of magnitude than the net gain? In other words, how significant is the inevitable worker dislocation relative to the net job gain? Although intraindustry netting makes it impossible to disaggregate job creation and destruction very far using industry-based data, it may be possible to discern which broad sectors experience the largest effects.

\section{SUMMARY}

Gross flow data, for all their faults, provide a perspective on the U.S. labor market that cannot be obtained from any other source. This paper studies three approaches to measuring gross flows of workers and jobs, including a new, broadly based measure based on detalled industry employment data. Each of the measures is flawed in a different way, but an important message comes through nevertheless: Both seasonal and business cycle downturns are dominated by increases in job destruction, not by declines in job creation. This may have interesting and important implications for macroeconomics, but analysis of gross job creation and destruction is a relatively undeveloped area of macroeconomics.

The data also point to a striking fact about the most recent business cycle: Job destruction during the downturn appears to have stayed at very low levels compared with previous reces. sions. Moreover, in contrast to previous recoveries, there was no surge in job creation following the trough.

\section{REFERENCES}

Abowd, John M., and Arnold Zeilner. "Estimating Gross Labor Force Flows," Joumal of Business and Economic Statistics (July 1985), pp, 254-83.

Abraham, Katharine G., and Lawrence F. Katz. "Cyclical Unemployment: Sectoral Shifus of Aggregate Distufbances?" Journal of Political Economy (June 1986), pp. 507-22.

Blanchard, Olivier Jean, and Peter Diamond, "The Cyclical Behavior of the Gross Flows of U.S. Workers," Brookings Papers on Economic Activity (1990, No. 2), pp. 85-155.

Burda, Michael, and Charles Wyplosz. "Gross Labor Market Flows in Europe: Some Stylized Facts;" Centre for Economic Policy Research Discussion Paper No. 439 (August 1990).

Davis, Steven J., and John Hattiwanger. "Qross Job Creation, Gross Job Destruction, and Employment Reallocation," Quarterly Journal of Economics (August 1992), pp. 819-63. 
and

"Gross Job Creation and Destruction: Microeconomic Evidence and Macroeconomic implications," NBER Macroeconomics Annual (1990) pp. 128-86.

Kreisler, Stephen. "BLS Establishment Estimates Revised to Incorporate March 1992 Benchmarks and Historical Corrections;" Employment and Earnings (U.S. Department of Labor, Bureau of Labor Statistics, June 1993), pp. 6-12

Lifen, David M. "Sectoral Shifts and Cyclical Unemployment," Journal of Political Economy (August 1982), pp. $77-93$.
Poterba, James M., and Lawrence H. Summers. "Reporting Errors and Labor Market Dynamics," Econometrica (November 1986), pp. 1319-38.

Shleifer, Andrel. "Implementation Cycles," Journal of Political Economy (December 1986), pp. 1163-90.

Uchitelle, Louis. "Wob Loss in Recession: Scratch Those Figures;" The New York Times, May 7, 1993.

U.S. Department of Labor, Bureau of Labor Statistics, $B L S$ Handbook of Methods, Bultetin 2414. U.S. Government Printing Office, September 1992.

\section{Appendix}

\section{Constructing Job Creation and Destruction Using Industry Employment Data}

This appendix describes fully the procedure used to generate the job creation and destruction series described in the Industry Data section. The raw data are employment levels for 606 industries and are not seasonally adjusted. They are a mixture of two-, three- and fourdigit SIC industries with varying start dates. The following steps detail the procedure.

1. For each two- or three-digit industry for which three- or four-digit subindustries are defined, a new residual industry is defined by subtracting employment in all of the subindustries from the total. The original two- or three-digit industry is then dropped from the data, leaving a set of non-overlapping industries that still include all employment in the original set of industries. In cases where four-digit industries start before three-digit "parent" industries, the two-digit residual is created by subtracting only employment in the four-digit industry from employment in the two-digit industry until the three-digit industry starts. After this point, both the four-digit industry and three-digit residual are subtracted from employment in the twodigit industry to get the two-digit residual. In some cases, the subindustries partition the entire industry, leaving no employment in the residual industry. If data for a two-digit industry start after the start date, the corresponding residual industry is dropped though some three- or four-digit subindustries may be includ. ed if their data go back to the start date).

2. A start date is chosen, say 1947 all industries start in January). All three-digit industries that start after 1947 and are part of a two-digit in- dustry not in the 1947 data are dropped. If a four-digit industry starts after 1947 and is part of a three-digit industry that starts after 1947 , and the three-digit industry is part of a twodigit industry that starts after 1947, the fourdigit industry is dropped. Three- or four-digit industries that start after 1947 but are part of a two-digit industry that starts in or before 1947 are retained, however. These will be referred to below as new industries and are all treated as spin-offs of the appropriate residual industry.

In some cases four-digit subindustries start before their parent three-digit industries. In this case, the three-digit residual industry is treated as a new industry that spins off from the appropriate two-digit residual and is considered zero until its start date.

3. In months when no new industries start (most months), job creation and destruction are calculated by totaling employment in industries where employment change is positive and negative, respectively.

4. In the starting month for a new industry, the data show employment going from zero to some positive number in the new industry and show a drop of the same amount in the residual industry (plus the growth of the rest of the residual industry). These changes are induced by reclassification of jobs, not job creation or destruction. ${ }^{1}$ Therefore, employment in the new $^{2}$ industry is added to employment in the residual industry and the new industry is ignored in creating job creation and destruction for that month. With this proviso, the job creation and

\footnotetext{
1Davis and Haltiwanger hande new establishments differently because the birth of an establishment reakly does correspond to job creation.
} 
destruction totals can be calculated by summing employment in industries in which employment change is positive and negative, respectively.

5. The final series for gross job creation, gross job destruction and total employment in the industries under consideration are separately seasonally adjusted using $\mathrm{X}-11$.

The three following examples may help to clarify the procedure.

\begin{tabular}{lr}
\multicolumn{2}{c}{ Example 1} \\
SIC & Starts \\
& \\
17 & 1972 \\
171 & 1958 \\
172 & 1958 \\
173 & 1958 \\
174 & 1972 \\
175 & 1972 \\
176 & 1958
\end{tabular}

'The residual industry would be

SIC17R = SIC17 - SIC171 - SIC172 - SIC173

$$
\text { - SIC174 - SIC175 - SIC176. }
$$

If the start date for Example 1 were 1947, all of these industries would be dropped. If the start date were 1972, they would all be included. If the start date were 1958, SIC17R, SIC174 and SIC175 would be dropped, but SIC171, SIC172, SIC173 and SIC176 would be included.

\section{Example 2}

$\begin{array}{ll}\text { SIC } & \text { Starts } \\ & \\ 27 & 1939 \\ 275 & 1958 \\ 2752 & 1972 \\ 2759 & 1972\end{array}$

Residual industries

$\mathrm{SIC} 275 \mathrm{R}=\mathrm{SIC} 275-\mathrm{SIC} 2752-\mathrm{SIC} 2759$

and

$$
\begin{aligned}
\mathrm{SIC} 27 \mathrm{R}= & \mathrm{SIC} 27-\mathrm{SIC} 275 \mathrm{R} \\
& -\mathrm{SIC} 2752-\operatorname{SIC} 2759 \\
& - \text { (other subindustries of SIC27) }
\end{aligned}
$$

would be created. SIC27 and SIC275 would be dropped, and SIC275R = SIC275 until 1972. If the start date is 1947 , SIC275R is treated as a new industry in 1958. SIC2752 and SIC2759 are new industries in 1972.

$$
\begin{array}{lr}
\multicolumn{2}{c}{\text { Example } 3} \\
\text { SIC } & \text { Starts } \\
& \\
41 & 1958 \\
411 & 1972 \\
412 & 1958 \\
413 & 1947 \\
415 & 1972
\end{array}
$$

If the start date is 1947 in this example, only data from SIC413 would be used. If the start date is 1958 or later, SIC41R and all of the three-digit industries would be included. 